\title{
Helminth Glycans at the Host-Parasite Interface and Their Potential for Developing Novel Therapeutics
}

\author{
Myrna J. M. Bunte*, Arjen Schots, Jan E. Kammenga and Ruud H. P. Wilbers \\ Laboratory of Nematology, Plant Sciences Group, Wageningen University and Research, Wageningen, Netherlands
}

Helminths are parasitic worms that have successfully co-evolved with their host immune system to sustain long-term infections. Their successful parasitism is mainly facilitated by modulation of the host immune system via the release of excretory-secretory (ES) products covered with glycan motifs such as Lewis X, fucosylated LDN, phosphorylcholine and tyvelose. Evidence is accumulating that these glycans play key roles in different aspects of helminth infection including interactions with immune cells for recognition and evasion of host defences. Moreover, antigenic properties of glycans can be exploited for improving the efficacy of anti-helminthic vaccines. Here, we illustrate that glycans have the potential to open new avenues for the development of novel biopharmaceuticals and effective vaccines based on helminth glycoproteins.

OPEN ACCESS

Edited by:

Michael C. Jewett, Northwestern University,

United States

Reviewed by:

Chang-Chun Ling,

University of Calgary, Canada

*Correspondence:

Myrna J. M. Bunte

myrna.bunte@wur.nı

Specialty section:

This article was submitted to

Glycoscience,

a section of the journal

Frontiers in Molecular Biosciences

Received: 02 November 2021 Accepted: 20 December 2021 Published: 10 January 2022

Citation:

Bunte MJM, Schots A, Kammenga JE and Wilbers RHP (2022) Helminth

Glycans at the Host-Parasite Interface and Their Potential for Developing

Novel Therapeutics.

Front. Mol. Biosci. 8:807821. doi: 10.3389/fmolb.2021.807821
Keywords: helminths, glycans, vaccines, immunomodulation, biopharmaceuticals

\section{INTRODUCTION}

Glycosylation is one of the most common post-translational modifications and contributes substantially to the molecular makeup of almost all living organisms. For infectious agents glycans play an important role in the interaction with their host in order to establish a successful infection. For example, glycosylation of the viral envelope proteins haemagglutinin and neuraminidase of influenza A impacts virus infectivity, virulence and host immune responses (Deshpande et al., 1987; Li et al., 1993; Schulze, 1997). Alternatively, impaired glycosylation of surface glycoproteins of the bacterium Campylobacter jejuni affects interactions with the host and results in reduced intestinal colonisation (Szymanski et al., 2002). For parasitic helminths, various glycans mediate the modulation of host immune responses, which benefits the establishment of long-term infections. Besides the advantages for the parasite, immunomodulatory effects could also be considered valuable for the host. Evidence is accumulating that areas where helminth infections are endemic are associated with a lower incidence of inflammatory diseases, like allergies and autoimmune diseases (Zaccone et al., 2006; Maizels and Yazdanbakhsh, 2008). The "hygiene hypothesis" and more recently the "old friends" hypothesis suggest that the absence of co-evolved microbes, including helminths, leads to defects in the establishment of immune regulatory networks (Rook, 2010). The lack of immunomodulatory effects in the absence of such infections could contribute to the development of inflammatory diseases, but also potentially immunological hyperactivity during SARS-CoV-2 (COVID-19) infection (Fonte et al., 2020; Hays et al., 2020; Gebrecherkos et al., 2021). Recent advances in glycobiology have contributed to further understanding of the interaction between glycosylated helminth products and the host immune system. Yet, there is still a lack of knowledge on the effects of many unique and complex helminth glycans on host immune responses. In this review we highlight the untapped 


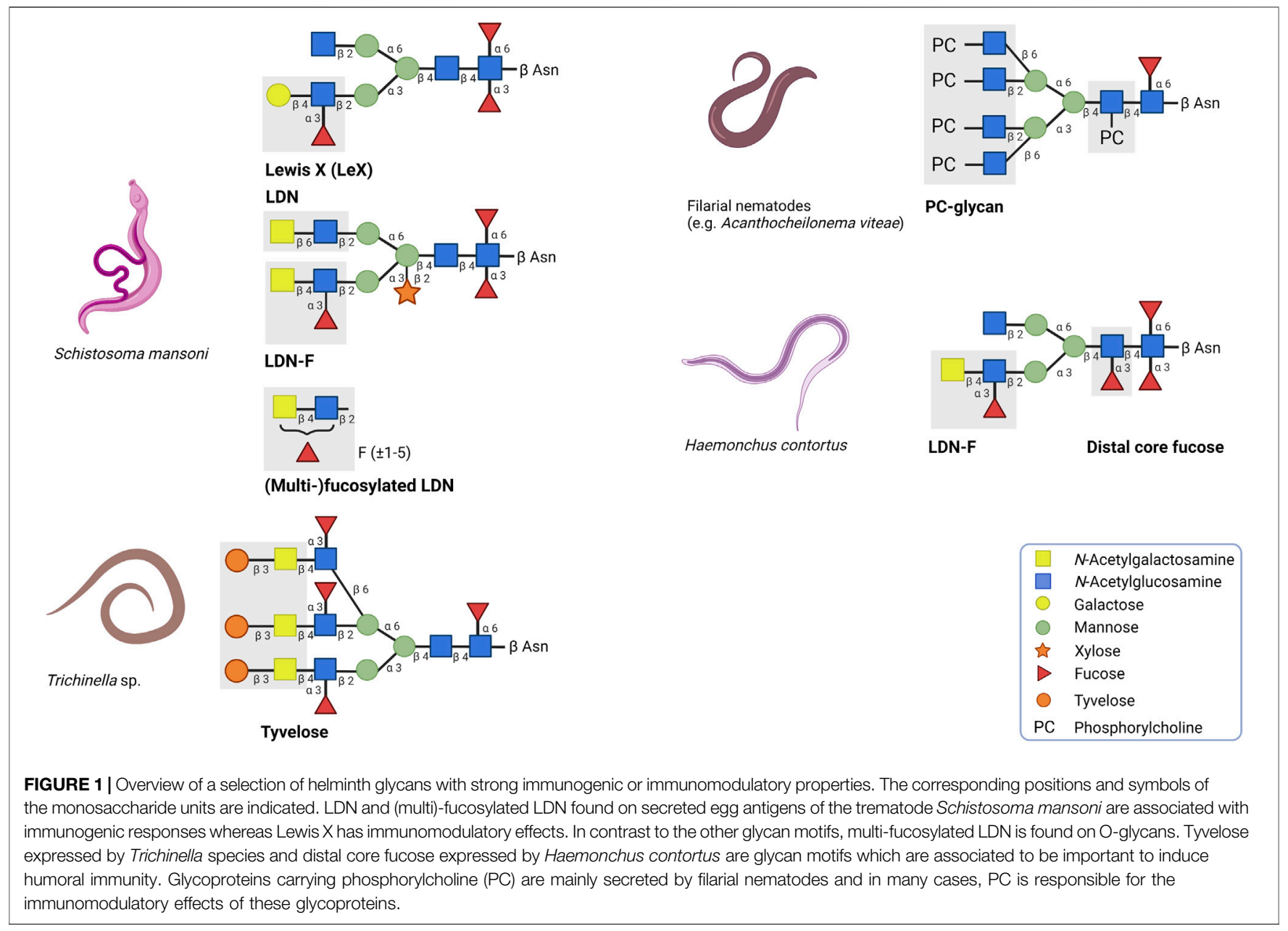

potential of these unique helminth glycans for the development of successful helminth biopharmaceuticals and vaccines.

\section{Helminth Glycans and Their Role in PRR Signalling}

Glycans on most helminth-released ES products play a role in the recognition by host innate immune cells. Upon infection, the glycan structures on ES products are recognised by pattern recognition receptors (PRRs), located on the surface of innate immune cells, such as dendritic cells (DCs) (Everts et al., 2010). For DCs, recognition and binding of an antigen to PRRs results in initiation of internal signalling pathways leading to the maturation of the DC itself. Mature DCs are able to release cytokines and mediate the polarisation of different T helper (Th) cell subsets including Th1, Th2, Th17 and regulatory $\mathrm{T}$ cells (Walsh and Mills, 2013).

Different classes of PRRs, such as Toll-Like Receptors (TLRs) and C-type Lectin Receptors (CLRs), bind to specific glycan motifs and mediate internalisation to initiate an appropriate immune response. Antigen recognition by TLRs generally results in priming immature DCs to induce the production of pro-inflammatory cytokines and costimulatory molecules that contribute to the maturation of naive $\mathrm{CD}^{+} \mathrm{T}$ helper cells into Th1 or Th17 cells (Kapsenberg, 2003; Medzhitov, 2007; Weaver et al., 2007). However, TLR recognition of helminth antigens is associated with lower expression of pro-inflammatory cytokines and polarisation towards Th2 cells (MacDonald and Maizels, 2008). For example, the filarial nematode glycoprotein ES-62 interacts with TLR4 on immature DCs, thereby initiating MyD88-dependent signalling cascades that lead to maturation of DCs and cytokine release. Subsequently, mature DCs will promote the differentiation of Th2 cells (Goodridge et al., 2005). N-glycans of ES-62 are characterised by the presence of phosphorylcholine (PC) motifs (Figure 1) (Harnett et al., 2003). Studies using PC-conjugated ovalbumin (PC-OVA) demonstrated that PC-OVA mimics the effects of ES-62 on DCs in a TLR4- and MyD88-dependent manner (Goodridge et al., 2007). This suggests that the PC motif is responsible for the interaction of ES-62 with DCs via TLR ligation.

The CLR family of receptors have distinct binding properties to specific carbohydrate motifs (Weis et al., 1998; Zelensky and Gready, 2005). Carbohydrate structures are often bound in a calcium-dependent manner to the highly conserved carbohydrate recognition domain of the receptor. Dendritic 
cell-specific intracellular adhesion molecule-3-grabbing nonintegrin (DC-SIGN), macrophage galactose-type C-type lectin (MGL) and mannose receptor (MR) are the most prominent CLRs described regarding helminth glycoprotein recognition (Prasanphanich et al., 2013). DC-SIGN is highly expressed on the surface of DCs and can recognise the glycan motifs Lewis X (Galß1-4(Fuca1-3)GlcNAc; LeX) and LDN-F (GalNAc $\beta 1-4$ (Fuca1-3)GlcNAc), which are found on secreted egg antigens of the trematode Schistosoma mansoni (Figure 1) (van Die et al., 2003; van Liempt et al., 2007). LeX binding to DC-SIGN induces the production of the anti-inflammatory cytokine IL-10 and contributes to a modified Th2 response (Gringhuis et al., 2014; Wilbers et al., 2017). MGL binds and internalises glycoproteins with terminal $\beta$-GalNAc residues, such as LDN (GalNAc $\beta 1-4 \mathrm{GlcNAc}$ ) and LDN-F, whereas MR recognises mannose- and fucose-containing glycans (Taylor et al., 1992; Denda-Nagai et al., 2002; van Vliet et al., 2005). Binding of the LeX-carrying glycoprotein omega-1 by MR has demonstrated to facilitate binding and internalisation of omega-1 by DCs (Everts et al., 2012; Wilbers et al., 2017).

Although there are strong indications that glycans play an important role in immune recognition, for many helminthderived glycoproteins it is still unknown how their glycans interact with immune cells and contribute to the modulation of the host immune system. Therefore, a deeper understanding is required of glycan interaction with PRRs and innate immune cells.

\section{Antibody Responses to Helminth Glycans}

Many helminth-derived products can initiate a humoral response by inducing the generation of antibodies. A large part of these antibodies binds specifically to the glycan structures on ES products, indicating that glycans can serve as epitopes. In some cases, antibodies against these glycan epitopes reduce an infection. An example of such a glycan epitope is tyvelose $(\beta 3,6-$ dideoxy-D-arabinohexose), a glycan modification found on the glycoprotein TSL-1, which is excreted by Trichinella spiralis during the infective larval muscular phase (L1) (Figure 1) (Reason et al., 1994). During this phase, IgG antibody responses are induced that predominantly target the $\beta$ anomeric tyvelose on TSL-1 (Appleton et al., 1988; Appleton et al., 1991; Ellis et al., 1997). These anti-tyvelose antibodies may play an important role in host-protection. In an in vitro model with intestinal epithelial cells, it was demonstrated that the tyvelose-specific antibodies inhibit the invasion of $T$. spiralis (McVay et al., 1998; McVay et al., 2000). In addition, the presence of these antibodies causes a rapid expulsion of L1 larvae, eliminating $99 \%$ of a total oral challenge dose in rats (Appleton and McGregor, 1984; Appleton et al., 1988; Bell et al., 1992; Ellis et al., 1994). The induced immunity can provide longterm protection (up to several months) and can be transferred to offspring (Bullick et al., 1984; Appleton et al., 1985).

Although anti-tyvelose antibodies can induce high-level protection against L1 larvae, these antibodies are not providing protective immunity against intestinal stages of infection (Goyal et al., 2002). This led to the idea that the presence of tyvelose may also offer protection for the parasite, since the expression of tyvelose and its associated immune response is specific for L1-staged larvae (Denkers et al., 1990; Robinson et al., 1995). By the time the host immune system has generated the required antibodies, the parasite continued its development and lost the tyvelose epitope. In this way, the strong antibody response may serve as a smoke screen to divert the immune system away from effective immune responses. However, there is limited evidence supporting this theory, so more research is required to further study the role of tyvelose during infection and in establishing protective immunity. Apart from its role in protection, anti-tyvelose antibodies may offer possibilities in terms of diagnostics. Immobilised anti-tyvelose monoclonal antibodies can relatively easy capture the major secreted TSL-1 antigens with high specificity and high sensitivity, which makes the antibodies suitable to be incorporated into serodiagnosis of human Trichinella infection (Escalante et al., 2004).

In case of Schistosoma mansoni infection, the host immune system encounters various highly glycosylated helminth-derived antigens. Throughout the life cycle, S. mansoni expresses a wide variety of glycan motifs on its $\mathrm{N}$ - and O-glycans as well as glycolipids. These motifs include LDN, (multi-)fucosylated LDN and LeX (Smit et al., 2015). Especially (multi-) fucosylated LDN glycan motifs are highly immunogenic and are targeted by IgM antibodies (and to a lesser extent IgG antibodies) in S. mansoni infected people (van Remoortere et al., 2001; Kariuki et al., 2008; Prasanphanich et al., 2014). Furthermore, primates vaccinated with radiation-attenuated (RA) cercariae exhibited high levels of IgM and IgG antibodies against multi-fucosylated glycan epitopes (Yang et al., 2019). However, compared to multi-fucosylated glycans, LDN-F and LeX induce lower levels of antibodies, primarily of the IgM class (van Remoortere et al., 2001; Naus et al., 2003; Van Remoortere et al., 2003). This reduced immunogenicity could be explained by the fact that expressed LDN-F and LeX motifs are shared with the host (Hokke and Deelder, 2001; Van Remoortere et al., 2003; Hokke and van Diepen, 2017). By mimicking host-like glycans, $S$. mansoni could have gained the opportunity to evade the host immune system to create a suitable micro-environment.

\section{The Role of Glycans in Helminth Immunomodulation}

Immunomodulation serves as an important survival strategy for helminth parasites. Biasing the host immune system towards a modified type 2 immune response results in a more antiinflammatory status, which decreases the chances of elimination. Glycans play an important role in the modulation of immune signalling via CLRs on DCs, thereby facilitating internalisation of helminth-released products and subsequent alteration of the immune response. For example, LeX mediates the internalisation of the $S$. mansoni egg antigen omega- 1 into DCs via the MR and DC-SIGN receptors (Steinfelder et al., 2009; Everts et al., 2012; Wilbers et al., 2017). Within the cell omega-1 has RNase activity, which reduces the activation and maturation of DCs, thereby biasing towards a Th2 response (Figure 2). The immunomodulatory properties of the LeX motif by itself have 


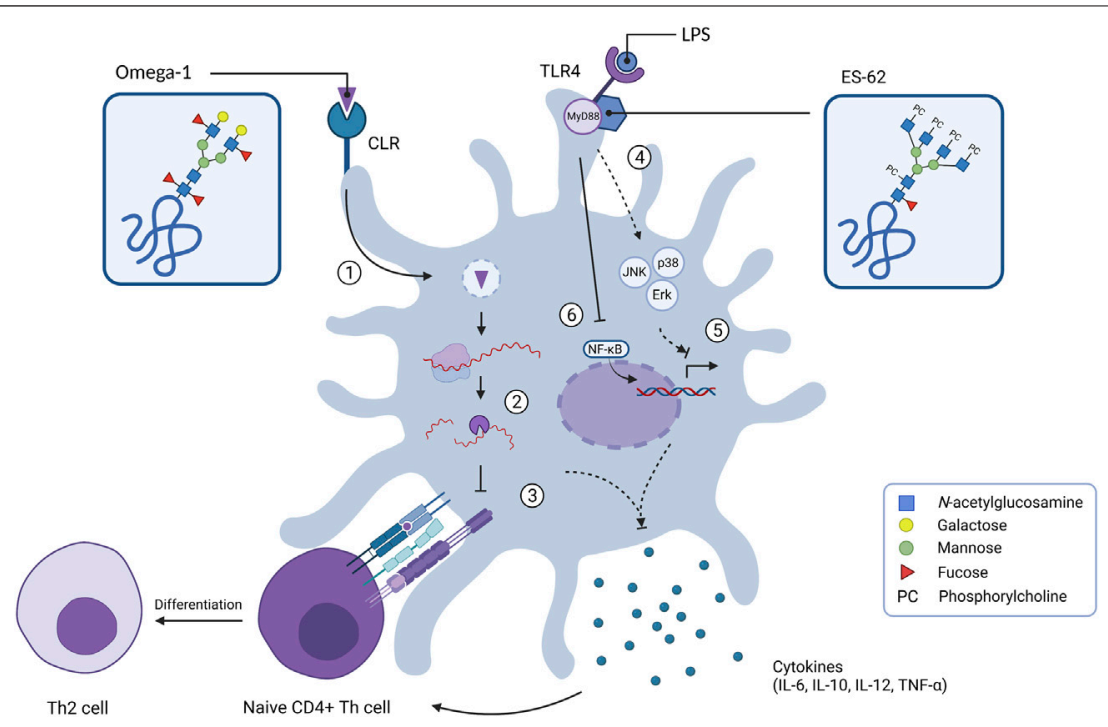

FIGURE 2 | Internal signalling of dendritic cells upon exposure of glycoproteins omega-1 and ES-62. C-type lectin receptors can bind various glycan motifs such as LeX on omega-1, which results in uptake of the extracellular antigen. After internalisation in endosomes (1), omega-1 translocates to the cytosol where it interferes with protein translation by exhibiting RNase activity on messenger RNA and ribosomal RNA (2). This suppresses DC maturation by inhibiting IL-12 cytokine release whilst enhancing IL-10 production and down-regulation of co-stimulatory molecules such as CD86. This ultimately results in T helper 2 (Th2) cell polarisation (3). Glycoprotein ES-62 biases the immune system towards an anti-inflammatory/Th2 response as it is able to mediate the LPS-induced TLR4 signalling by regulating the activity of kinases Erk, JNK and p38 via adaptor molecule MyD88 (4). This leads to down-regulation of gene transcription of Th1-associated cytokines (IL-6, IL-12p38 subunit and TNF-a) (5). ES-62 inhibits the production of IL-12p40 subunit by preventing the binding of transcription factor NF-kB to the IL-12 promotor (6).

also been investigated using lacto- $N$-fucopentaose III (LNFPIII), a LeX carrying penta-saccharide found in breast milk and urine of pregnant women (Ko et al., 1990). This LNFPIII glyco-conjugate promotes an anti-inflammatory response by the induction of alternatively activated macrophages (Atochina et al., 2008). Macrophage and DC activation by LNFPIII appears to be dependent on a1,3-linked fucose of the LeX motif, suggesting that the presence of $\alpha 1,3$-linked fucose is necessary for LNFPIII to exert its effects (Tundup et al., 2015).

In addition, human filarial nematodes, such as Brugia malayi, Wuchereria bancrofi and Onchocerca volvulus secrete phosphorylcholine (PC)-containing glycoproteins, which can drive immunomodulation (Forsyth et al., 1985; Harnett et al., 1989; Maizels et al., 1987). The best characterised PC-carrying glycoprotein is ES-62 and is found in the ES products of the rodent filarial nematode Acanthocheilonema viteae (Harnett et al., 1989). ES-62 has immunomodulatory effects on a wide variety of immune cells including $\mathrm{T}$ and $\mathrm{B}$ cells, macrophages and DCs (Pineda et al., 2014). ES-62 polarizes the immune system towards a type 2 immune response by inducing Th2 cells instead of Th1 cells (Harnett et al., 1999). When the PC motif is removed, this Th2 polarisation is balanced out, suggesting that $\mathrm{PC}$ is predominantly responsible for the immunomodulatory effects of ES-62 (Houston et al., 2000). Interestingly, PCconjugates mimic several of these immunomodulatory effects, such as the TLR4-dependent interaction with DCs (Goodridge et al., 2005). PC-conjugates also dampen the activation of DCs, which results in reduced expression of costimulatory molecules and Th1/Th17-polarising cytokines IL-12, IL-6 and TNF- $\alpha$ (Figure 2) (Goodridge et al., 2004; Goodridge et al., 2007;
Lumb et al., 2017). In B cells, exposure to PC-conjugates results in interference of activation and proliferation of these immune cells (Harnett and Harnett, 1993). The presence of PC on ES-62 causes desensitisation of the B cell receptor (BCR) by inhibiting key proliferation pathways (Deehan et al., 2001). Mice exposed to PC-conjugates produced high levels of antiinflammatory cytokine IL-10 and IgM antibodies, which are also abundant during filarial nematode infections (Al-Qaoud et al., 1998). Therefore, it is reasonable to state that PC by itself is acting as an active ingredient on ES-62 as it is largely mediating the immunomodulatory effects of this helminth ES product.

Overall, these examples indicate that glycan motifs such as LeX and PC have broad immunomodulatory properties, which may be interesting for the development of biopharmaceuticals. Attempts have been made to explore the potential of helminth-derived glycoproteins to serve as therapeutic agents. For example, plantproduced recombinant omega-1 with LeX-carrying glycans was able to reduce body weight, fat mass and food intake of obese mice and improve their insulin sensitivity and glucose tolerance (van der Zande et al., 2021). In addition, immunomodulatory effects of the PC-glycoprotein ES-62 led to the design and synthesis of small molecule analogues (SMAs) that mimicked the chemical structure of PC (Al-Riyami et al., 2013). Besides providing additional evidence that immunomodulatory properties of ES-62 depend on PC, these SMAs offer solutions for treatment against immune disorders. Studies in mouse models of inflammationassociated diseases such as rheumatoid arthritis, systemic lupus erythematosus and asthma demonstrated that these SMAs possess anti-inflammatory properties similar to ES-62 (Al-Riyami et al., 2013; Rzepecka et al., 2014; Al-Riyami et al., 2015; Rzepecka et al., 
2015; Coltherd et al., 2016; Janicova et al., 2016; Lumb et al., 2017; Doonan et al., 2018; Suckling et al., 2018). Since ES-62 is immunogenic and hard to obtain on large scale, SMAs exhibit great therapeutic potential against inflammation-associated diseases.

\section{Challenges and Opportunities of Glycans in Helminth Vaccine Development}

To date, helminths still pose a serious threat for human and animal health. The current treatment of human and animal helminth infections primarily consists of anthelminthic drugs in mass drug administration (MDA) programs. However, anthelminthic drugs are never fully effective to eradicate helminths from their host, so re-administration is necessary. This may result in reduced efficacy through the development of resistance against anthelminthic drugs (De Clercq et al., 1997; Ismail et al., 1999; Melman et al., 2009; Osei-Atweneboana et al., 2011; Sutherland and Leathwick, 2011; Nana-Djeunga et al., 2014; Crellen et al., 2016). For this reason, vaccines against helminth infections are proposed as a more effective and durable treatment.

Given that some glycans seem to induce a potent immune response, the idea has arisen that helminth-derived glycans aid in the efficacy vaccines. Attempts have been made to develop a vaccine against Schistosoma mansoni by using radiationattenuated (RA) cercariae. Vaccination of primates with RA cercariae demonstrated to provide protection against Schistosoma infection. In vaccinated chimpanzees, the faecal egg count and the level of circulating cathodic antigens (CCA) were reduced by 38 and 46\%, respectively, compared to nonvaccinated control animals (Eberl et al., 2001a). Baboons vaccinated with RA cercariae developed even higher protection since their worm burden, faecal egg count and CCA were reduced by up to 86,94 and $99 \%$, respectively, compared to nonvaccinated baboons (Kariuki et al., 2004). This induced protection correlates with high levels of specific $\operatorname{IgM}$ and $\operatorname{IgG}$ antibodies targeting RA cercariae-derived glycan epitopes (Eberl et al., 2001b; Yang et al., 2019). High titres of IgG against (multi-) fucosylated glycan epitopes were observed in RA vaccinated baboons (Yang et al., 2019). These IgG levels remained high until 6 weeks post-challenge, suggesting a potent role of these fucose-targeting IgG antibodies in protection. Although, these results are promising, the induced protection could not be sustained for long-term (Kariuki et al., 2004). Therefore, more research is required to improve sustained efficacy of RA cercariae as vaccine.

To combat livestock-infecting helminths, only three commercial vaccines are available on the market but many vaccines are still in development (Claerebout and Geldhof, 2020). Many helminth vaccines rely on life-attenuated parasites, parasite extracts or purified native antigens, which require the use of donor animals to produce the important ingredients of the vaccines. Besides ethical issues it is challenging to collect enough parasite material for largescale vaccine production. Therefore, the use of recombinant production systems has been explored, resulting in more than 100 vaccine studies with recombinant helminth antigens, including 80 different antigens targeting 22 helminth species
(Geldhof et al., 2007). However, only few recombinant vaccines induce high-level protection against helminth infection (Geldhof et al., 2008; Hewitson and Maizels, 2014). The choice for the bacterium Escherichia coli as recombinant expression system could be a possible explanation why most recombinant helminth vaccines fail to induce high-level protection, since $E$. coli is incapable to perform complex eukaryotic post-translational modifications like glycosylation. Therefore, other eukaryotic expression systems have been considered to produce recombinant helminth vaccines with complex post-translational modifications.

For example, different expression systems have been investigated for the production of recombinant activationassociated secreted protein 1 of Ostertagia ostertagi (OoASP1). Vaccination of cows with a native ASP-enriched fraction made from an ES-thiol fraction, of which OoASP-1 and OoASP-2 are the most abundant antigens, resulted in $74 \%$ reduction of faecal egg counts (Geldhof et al., 2002; Geldhof et al., 2003; Meyvis et al., 2007). To convert this native vaccine to a recombinant version, expression of OoASP-1 in the yeast Pichia pastoris and the baculovirus insect cell system was explored. Pichia pastorisexpressed OoASP-1 showed a less potent immune response than native OoASP-1 and both recombinant OoASP-1 variants failed to induce protection upon re-infection (Geldhof et al., 2008; González-Hernández et al., 2016). A reason for this could be that native OoASP-1 is differently glycosylated in recombinant systems. Incorrect glycosylation could impact potentially important glycan epitopes, the correct folding of the protein or the interaction with immune cells. Removal of the glycans of the ES-thiol fraction demonstrated that antibody binding to these antigens is not affected by the lack of glycosylation, whereas changing protein confirmation by denaturation/reduction did (Meyvis et al., 2008). Improper folding of recombinant OoASP-1 by an altered glycan composition could therefore result in unreachable epitopes, which might be required for inducing protective immune responses.

The development of recombinant vaccines against Haemonchus contortus infection has faced similar challenges. Currently, the $H$. contortus vaccine Barbervax is approved and marketed in Australia and is based on ES material enriched with glycoproteins H11 and H-gal-GP (Nisbet et al., 2016). The production of Barbarvax relies on conventional isolation of ES material from parasites from infected donor sheep. Therefore, other strategies to employ $H$. contortus glycoproteins as recombinant vaccine candidates have been explored. Glycoprotein $\mathrm{H} 11$ has been subjected to vaccine trials as vaccination with an extract enriched with $\mathrm{H} 11$ demonstrated high levels of protection and the generated antibodies were mostly directed towards H11 (Munn et al., 1993). Initial vaccine trials using recombinant $\mathrm{H} 11$ produced in $E$. coli and baculovirus insect cell system were unsuccessful to induce protection (Knox et al., 2003; Newton and Meeusen, 2003; Reszka et al., 2007). Failure has mainly been directed to the differences in post-translational modifications that impacted the glycosylation and folding of H11. Mass spectrometry analysis showed that $\mathrm{N}$-glycans of $\mathrm{H} 11$ are highly fucosylated and contain a1,3- and a1,6-linked core fucoses on the proximal GlcNAc and a1,3-linked fucose on the distal core GlcNAc (Figure 1) (Haslam 
et al., 1996). Most of the generated antibodies were directed against these $\mathrm{H} 11$ glycan epitopes. Moreover, a1,3-linked core fucose induces the production of $\operatorname{IgE}$ antibodies, which correlated with the induction of protection (van Die et al., 1999; Kooyman et al., 2000). This suggests that $\alpha 1,3$-linked core fucose serves as an important epitope to induce humoral immunity. To test whether recombinant fucosylated $\mathrm{H} 11$ induces protection, $\mathrm{H} 11$ was expressed in the free-living nematode Caenorhabditis elegans since it has the required glycan machinery to mimic the native glycan composition of H11 (Nguyen et al., 2007; Roberts et al., 2013). Although C. elegans expressed H11 carried N-glycans with a1,3- and a1,6-linked core fucoses and a1,3-linked distal core fucose, no protection was observed against $H$. contortus challenge infection (Roberts et al., 2013). The lack of efficacy could be attributed to subtle differences in the glycan composition of $\mathrm{H} 11$ upon expression in C. elegans. For instance, C. elegans expressed H11 lacks LDN-F, a glycan motif previously shown to be correlated with protective immunity against $H$. contortus in lambs (Vervelde et al., 2003). Similarly, antibody responses to the O-glycan motif Gala1-3GalNAc glycan epitopes correlates with protection in lambs that are vaccinated with ES products of H. contortus (van Stijn et al., 2010).

Differences in glycan composition or glycan abundance could be the reason why recombinant vaccines against helminths are not able to induce protective immunity. Therefore, further mimicking the native glycan composition could improve the immunogenicity towards inducing sufficient protection.

\section{CONCLUSION}

There is substantial evidence that helminth glycans play a key role in establishing immunomodulatory and protective immune responses by the host. Although recent efforts have gained new

\section{REFERENCES}

Al-Qaoud, K., Fleischer, B., and Hoerauf, A. (1998). The Xid Defect Imparts Susceptibility to Experimental Murine Filariosis- -association with a Lack of Antibody and IL-10 Production by B Cells in Response to Phosphorylcholine. Int. Immunol. 10 (1), 17-25. doi:10.1093/intimm/10.1.17

Al-Riyami, L., Pineda, M. A., Rzepecka, J., Huggan, J. K., Khalaf, A. I., Suckling, C. J., et al. (2013). Designing Anti-inflammatory Drugs from Parasitic Worms: a Synthetic Small Molecule Analogue of the Acanthocheilonema Viteae Product ES-62 Prevents Development of Collagen-Induced Arthritis. J. Med. Chem. 56 (24), 9982-10002. doi:10.1021/jm401251p

Al-Riyami, L., Rodgers, D. T., Rzepecka, J., Pineda, M. A., Suckling, C. J., Harnett, M. M., et al. (2015). Protective Effect of Small Molecule Analogues of the Acanthocheilonema Viteae Secreted Product ES-62 on Oxazolone-Induced Ear Inflammation. Exp. Parasitol. 158, 18-22. doi:10.1016/j.exppara.2015.03.025

Appleton, J. A., McGregor, D. D., Baker, J., and Baker, J. A. (1985). Life-phase Specific Induction and Expression of Rapid Expulsion in Rats Suckling Trichinella Spiralis-Infected Dams. Immunology 55 (2), 225-232.

Appleton, J. A., Schain, L. R., McGregor, D. D., and Baker, J. A. (1988). Rapid Expulsion of Trichinella spiralis in Suckling Rats: Mediation by Monoclonal Antibodies. Immunology 65 (3), 487-492.

Appleton, J. A., Bell, R. G., Homan, W., and Van Knapen, F. (1991). Consensus on Trichinella spiralis Antigens and Antibodies. Parasitol. Today 7, 190-192. doi:10.1016/0169-4758(91)90135-b insights on the role of several helminth glycans at the host-parasite interface, many questions remain to be addressed. Technological advances in the field of glycobiology, including mass spectrometrybased glycomics, glycan-arrays and glyco-engineering, will allow us to unravel the complexity of helminth glycomes. In parallel, there is a need for recombinant expression systems that are able to produce helminth glycoproteins with a native glycan composition in order to study their role in immunogenicity and/or immunomodulation. Plants could serve as such expression system as it offers "engineering" of the post-translational machinery, resulting in tailor-made helminth glycan structures (Wilbers et al., 2017; Van Noort et al., 2020). Altogether this offers opportunities to exploit the untapped potential of helminth glycans to develop helminth-derived biopharmaceuticals, diagnostics and improved vaccines.

\section{AUTHOR CONTRIBUTIONS}

$\mathrm{MB}$ and RW wrote the manuscript with input from all other authors. All authors contributed to the article and approved the submitted version.

\section{FUNDING}

This work was supported by the TTW Veni Grant 16740 from Netherlands Organization for Scientific Research.

\section{ACKNOWLEDGMENTS}

We would like to thank Kim van Noort and Sardy Partowidjojo for their input in the initial phase of writing this manuscript.

Appleton, J. A., and McGregor, D. D. (1984). Rapid Expulsion of Trichinella spiralis in Suckling Rats. Science 226 (4670), 70-72. doi:10.1126/science.6474191

Atochina, O., Da'dara, A. A., Walker, M., and Harn, D. A. (2008). The Immunomodulatory Glycan LNFPIII Initiates Alternative Activation of Murine Macrophagesin Vivo. Immunology 125 (1), 111-121. doi:10.1111/ j.1365-2567.2008.02826.x

Bell, R. G., Appleton, J. A., Negrao-Correa, D. A., Adams, L. S., and Baker, J. A. (1992). Rapid Expulsion of Trichinella spiralis in Adult Rats Mediated by Monoclonal Antibodies of Distinct IgG Isotypes. Immunology 75 (3), 520-527.

Bullick, G. R., Russell, D. A., and Castro, G. A. (1984). Long Term Duration of the Rapid Rejection Response in Rats Infected with Trichinella spiralis. J. Parasitol. 70 (6), 981. doi:10.2307/3281654

Claerebout, E., and Geldhof, P. (2020). Helminth Vaccines in Ruminants. Vet. Clin. North America: Food Anim. Pract. 36 (1), 159-171. doi:10.1016/ j.cvfa.2019.10.001

Coltherd, J. C., Rodgers, D. T., Lawrie, R. E., Al-Riyami, L., Suckling, C. J., Harnett, W., et al. (2016). The Parasitic Worm-Derived Immunomodulator, ES-62 and its Drug-like Small Molecule Analogues Exhibit Therapeutic Potential in a Model of Chronic Asthma. Sci. Rep. 6 (1), 1-14. doi:10.1038/srep19224

Crellen, T., Walker, M., Lamberton, P. H. L., Kabatereine, N. B., Tukahebwa, E. M., Cotton, J. A., et al. (2016). Reduced Efficacy of Praziquantel AgainstSchistosoma mansoniIs Associated with Multiple Rounds of Mass Drug Administration. Clin. Infect. Dis. 63 (9), ciw506-1159. doi:10.1093/cid/ciw506

De Clercq, D., Dorny, P., Behnke, J., Sacko, M., Vercruysse, J., and Gilbert, F. (1997). Failure of Mebendazole in Treatment of Human Hookworm Infections 
in the Southern Region of Mali. Am. J. Trop. Med. Hyg. 57 (1), 25-30. doi:10.4269/ajtmh.1997.57.25

Deehan, M. R., Harnett, W., and Harnett, M. M. (2001). A Filarial NematodeSecreted Phosphorylcholine-Containing Glycoprotein Uncouples the B Cell Antigen Receptor from Extracellular Signal-Regulated Kinase-MitogenActivated Protein Kinase by Promoting the Surface Ig-Mediated Recruitment of Src Homology 2 Domain-Containing Tyrosine Phosphatase1 and Pac-1 Mitogen-Activated Kinase-Phosphatase. J. Immunol. 166 (12), 7462-7468. doi:10.4049/jimmunol.166.12.7462

Denda-Nagai, K., Kubota, N., Tsuiji, M., Kamata, M., and Irimura, T. (2002). Macrophage C-type Lectin on Bone Marrow-Derived Immature Dendritic Cells Is Involved in the Internalization of Glycosylated Antigens. Glycobiology 12 (7), 443-450. doi:10.1093/glycob/cwf061

Denkers, E. Y., Wassom, D. L., Krco, C. J., and Hayes, C. E. (1990). The Mouse Antibody Response to Trichinella spiralis Defines a Single, Immunodominant Epitope Shared by Multiple Antigens. J. Immunol. 144 (8), 3152-3159.

Deshpande, K. L., Fried, V. A., Ando, M., and Webster, R. G. (1987). Glycosylation Affects Cleavage of an H5N2 Influenza Virus Hemagglutinin and Regulates Virulence. Proc. Natl. Acad. Sci. 84 (1), 36-40. doi:10.1073/pnas.84.1.36

Doonan, J., Lumb, F. E., Pineda, M. A., Tarafdar, A., Crowe, J., Khan, A. M., et al. (2018). Protection against Arthritis by the Parasitic Worm Product ES-62, and its Drug-like Small Molecule Analogues, Is Associated with Inhibition of Osteoclastogenesis. Front. Immunol. 9, 1016. doi:10.3389/fimmu.2018.01016

Eberl, M., Langermans, J. A. M., Frost, P. A., Vervenne, R. A., van Dam, G. J., Deelder, A. M., et al. (2001a). Cellular and Humoral Immune Responses and protection against Schistosomes Induced by a Radiation-Attenuated Vaccine in Chimpanzees. Infect. Immun. 69 (9), 5352-5362. doi:10.1128/IAI.69.9.53525362.2001

Eberl, M., Langermans, J. A. M., Vervenne, R. A., Nyame, A. K., Cummings, R. D., Thomas, A. W., et al. (2001b). Antibodies to Glycans Dominate the Host Response to Schistosome Larvae and Eggs: Is Their Role Protective or Subversive? J. Infect. Dis. 183 (8), 1238-1247. doi:10.1086/319691

Ellis, L. A., McVay, C. S., Probert, M. A., Zhang, J., Bundle, D. R., Appleton, J. A., et al. (1997). Terminal $\beta$-linked Tyvelose Creates Unique Epitopes in Trichinella spiralis Glycan Antigens. Glycobiology 7 (3), 383-390. doi:10.1093/glycob/ 7.3.383

Ellis, L. A., Reason, A. J., Morris, H. R., Dell, A., Iglesias, R., Ubeira, F. M., et al. (1994). Glycans as Targets for Monoclonal Antibodies that Protect Rats against Trichinella spiralis. Glycobiology 4 (5), 585-592. doi:10.1093/glycob/4.5.585

Escalante, M., Romari's, F., Rodri'guez, M., Rodri'guez, E., Leiro, J., Ga'rate, M. T., et al. (2004). Evaluation of Trichinella spiralis Larva Group 1 Antigens for Serodiagnosis of Human Trichinellosis. J. Clin. Microbiol. 42 (9), 4060-4066. doi:10.1128/JCM.42.9.4060-4066.2004

Everts, B., Hussaarts, L., Driessen, N. N., Meevissen, M. H. J., Schramm, G., van der Ham, A. J., et al. (2012). Schistosome-derived omega-1 Drives Th2 Polarization by Suppressing Protein Synthesis Following Internalization by the Mannose Receptor. J. Exp. Med. 209 (10), 1753-1767. doi:10.1084/jem.20111381

Everts, B., Smits, H. H., Hokke, C. H., and Yazdanbakhsh, M. (2010). Helminths and Dendritic Cells: Sensing and Regulating via Pattern Recognition Receptors, Th2 and Treg Responses. Eur. J. Immunol. 40 (6), 1525-1537. doi:10.1002/ eji.200940109

Fonte, L., Acosta, A., Sarmiento, M. E., Ginori, M., García, G., and Norazmi, M. N. (2020). COVID-19 Lethality in Sub-saharan Africa and Helminth Immune Modulation. Front. Immunol. 11, 2459. doi:10.3389/fimmu.2020.574910

Forsyth, K. P., Spark, R., Kazura, J., Brown, G. V., Peters, P., Heywood, P., et al. (1985). A Monoclonal Antibody-Based Immunoradiometric Assay for Detection of Circulating Antigen in Bancroftian Filariasis. J. Immunol. 134 (2), 1172-1177.

Gebrecherkos, T., Gessesse, Z., Kebede, Y., Gebreegzabher, A., Tasew, G., Abdulkader, M., et al. (2021). Effect of Co-infection with Parasites on Severity of COVID-19. medRxiv. doi:10.1101/2021.02.02.21250995

Geldhof, P., Claerebout, E., Knox, D., Vercauteren, I., Looszova, A., and Vercruysse, J. (2002). Vaccination of Calves against Ostertagia Ostertagi with Cysteine Proteinase Enriched Protein Fractions. Parasite Immunol. 24 (5), 263-270. doi:10.1046/j.1365-3024.2002.00461.x

Geldhof, P., De Maere, V., Vercruysse, J., and Claerebout, E. (2007). Recombinant Expression Systems: the Obstacle to Helminth Vaccines? Trends Parasitol. 23 (11), 527-532. doi:10.1016/j.pt.2007.08.012
Geldhof, P., Meyvis, Y., Vercruysse, J., and Claerebout, E. (2008). Vaccine Testing of a Recombinant Activation-Associated Secreted Protein (ASP1) from Ostertagia Ostertagi. Parasite Immunol. 30 (1), 57-60. doi:10.1111/j.13653024.2007.01001.x

Geldhof, P., Vercauteren, I., Gevaert, K., Staes, A., Knox, D. P., Vandekerckhove, J., et al. (2003). Activation-associated Secreted Proteins Are the Most Abundant Antigens in a Host Protective Fraction from Ostertagia Ostertagi. Mol. Biochem. Parasitol. 128 (1), 111-114. doi:10.1016/S0166-6851(03)00044-6

González-Hernández, A., Van Coppernolle, S., Borloo, J., Van Meulder, F., Paerewijck, O., Peelaers, I., et al. (2016). Host Protective ASP-Based Vaccine against the Parasitic Nematode Ostertagia Ostertagi Triggers NK Cell Activation and Mixed IgG1-IgG2 Response. Sci. Rep. 6, 29496. doi:10.1038/ srep29496

Goodridge, H. S., Marshall, F. A., Else, K. J., Houston, K. M., Egan, C., Al-Riyami, L., et al. (2005). Immunomodulation via Novel Use of TLR4 by the Filarial Nematode Phosphorylcholine-Containing Secreted Product, ES-62. J. Immunol. 174 (1), 284-293. doi:10.4049/jimmunol.174.1.284

Goodridge, H. S., Marshall, F. A., Wilson, E. H., Houston, K. M., Liew, F. Y., Harnett, M. M., et al. (2004). In Vivo exposure of Murine Dendritic Cell and Macrophage Bone Marrow Progenitors to the Phosphorylcholine-Containing Filarial Nematode Glycoprotein ES-62 Polarizes Their Differentiation to an Anti-inflammatory Phenotype. Immunology 113 (4), 491-498. doi:10.1111/ j.1365-2567.2004.01993.x

Goodridge, H. S., McGuiness, S., Houston, K. M., Egan, C. A., al-Riyami, L., Alcocer, M. J. C., et al. (2007). Phosphorylcholine Mimics the Effects of ES-62 on Macrophages and Dendritic Cells. Parasite Immunol. 29 (3), 127-137. doi:10.1111/j.1365-3024.2006.00926.x

Goyal, P. K., Wheatcroft, J., and Wakelin, D. (2002). Tyvelose and Protective Responses to the Intestinal Stages of Trichinella spiralis. Parasitol. Int. 51 (1), 91-98. doi:10.1016/S1383-5769(02)00002-8

Gringhuis, S. I., Kaptein, T. M., Wevers, B. A., Mesman, A. W., and Geijtenbeek, T. B. H. (2014). Fucose-specific DC-SIGN Signalling Directs T Helper Cell Type-2 Responses via IKKe- and CYLD-dependent Bcl3 Activation. Nat. Commun. 5 (1), 1-13. doi:10.1038/ncomms4898

Harnett, W., and Harnett, M. M. (1993). Inhibition of Murine B Cell Proliferation and Down-Regulation of Protein Kinase C Levels by a PhosphorylcholineContaining Filarial Excretory-Secretory Product. J. Immunol. 151 (9), 4829-4837.

Harnett, W., Deehan, M. R., Houston, K. M., and Harnett, M. M. (1999). Immunomodulatory Properties of a Phosphorylcholine-Containing Secreted Filarial Glycoprotein. Parasite Immunol. 21 (12), 601-608. doi:10.1046/j.13653024.1999.00267.x

Harnett, W., Harnett, M., and Byron, O. (2003). Structural/Functional Aspects of ES-62 - A Secreted Immunomodulatory Phosphorylcholine-Containing Filarial Nematode Glycoprotein. Cpps 4 (1), 59-71. doi:10.2174/1389203033380368

Harnett, W., Worms, M. J., Kapil, A., Grainger, M., and Parkhouse, R. M. E. (1989). Origin, Kinetics of Circulation and Fatein Vivoof the Major ExcretorySecretory Product ofAcanthocheilonema Viteae. Parasitology 99 (2), 229-239. doi:10.1017/S0031182000058686

Haslam, S. M., Coles, G. C., Munn, E. A., Smith, T. S., Smith, H. F., Morris, H. R., et al. (1996). Haemonchus contortus Glycoproteins Contain N-Linked Oligosaccharides with Novel Highly Fucosylated Core Structures. J. Biol. Chem. 271 (48), 30561-30570. doi:10.1074/jbc.271.48.30561

Hays, R., Pierce, D., Giacomin, P., Loukas, A., Bourke, P., and McDermott, R. (2020). Helminth Coinfection and COVID-19: An Alternate Hypothesis. Plos Negl. Trop. Dis. 14 (8), e0008628. doi:10.1371/journal.pntd.0008628

Hewitson, J. P., and Maizels, R. M. (2014). Vaccination against Helminth Parasite Infections. Expert Rev. Vaccin. 13 (4), 473-487. doi:10.1586/ 14760584.2014.893195

Hokke, C. H., and Deelder, A. M. (2001). Schistosome Glycoconjugates in HostParasite Interplay. Glycoconjugate J. 18 (8), 573-587. doi:10.1023/A: 1020634602161

Hokke, C. H., and van Diepen, A. (2017). Helminth Glycomics - Glycan Repertoires and Host-Parasite Interactions. Mol. Biochem. Parasitol. 215, 47-57. doi:10.1023/A:102063460216110.1016/j.molbiopara.2016.12.001

Houston, K. M., Wilson, E. H., Eyres, L., Brombacher, F., Harnett, M. M., Alexander, J., et al. (2000). Presence of Phosphorylcholine on a Filarial Nematode Protein Influences Immunoglobulin G Subclass Response to the 
Molecule by an Interleukin-10-dependent Mechanism. Infect. Immun. 68 (9), 5466-5468. doi:10.1128/IAI.68.9.5466-5468.2000

Ismail, M., William, S., Day, T. A., Botros, S., Tao, L. F., Bennett, J. L., et al. (1999). Resistance to Praziquantel: Direct Evidence from Schistosoma Mansoni Isolated from Egyptian Villagers. Am. J. Trop. Med. Hyg. 60 (6), 932-935. doi:10.4269/ajtmh.1999.60.932

Janicova, L., Rzepecka, J., Rodgers, D. T., Doonan, J., Bell, K. S., Lumb, F. E., et al. (2016). Testing Small Molecule Analogues of theAcanthocheilonema Viteaeimmunomodulator ES-62 against Clinically Relevant Allergens. Parasite Immunol. 38 (6), 340-351. doi:10.1111/pim.12322

Kapsenberg, M. L. (2003). Dendritic-cell Control of Pathogen-Driven T-Cell Polarization. Nat. Rev. Immunol. 3 (12), 984-993. doi:10.1038/nri1246

Kariuki, T. M., Farah, I. O., Wilson, R. A., and Coulson, P. S. (2008). Antibodies Elicited by the Secretions from Schistosome Cercariae and Eggs Are Predominantly against Glycan Epitopes. Parasite Immunol. 30 (10), 554-562. doi:10.1111/j.1365-3024.2008.01054.x

Kariuki, T. M., Farah, I. O., Yole, D. S., Mwenda, J. M., Van Dam, G. J., Deelder, A. M., et al. (2004). Parameters of the Attenuated Schistosome Vaccine Evaluated in the Olive Baboon. Infect. Immun. 72 (9), 5526-5529. doi:10.1128/ IAI.72.9.5526-5529.2004

Knox, D. P., Redmond, D. L., Newlands, G. F., Skuce, P. J., Pettit, D., and Smith, W. D. (2003). The Nature and Prospects for Gut Membrane Proteins as Vaccine Candidates for Haemonchus contortus and Other Ruminant Trichostrongyloids. Int. J. Parasitol. 33 (11), 1129-1137. doi:10.1016/s00207519(03)00167-x

Ko, A. I., Drager, U. C., and Harn, D. A. (1990). A Schistosoma Mansoni Epitope Recognized by a Protective Monoclonal Antibody Is Identical to the Stagespecific Embryonic Antigen 1. Proc. Natl. Acad. Sci. 87 (11), 4159-4163. doi:10.1073/pnas.87.11.4159

Kooyman, S. H., Schallig, M. A., Van Leeuwen, A., Mackellar, J. F., Huntley, A. W., Cornelissen, L., et al. (2000). Protection in Lambs Vaccinated with Haemonchus contortus Antigens Is Age Related, and Correlates with IgE rather Than IgG1 Antibody. Parasite Immunol. 22 (1), 13-20. doi:10.1046/j.13653024.2000.00265.x

Li, S., Schulman, J., Itamura, S., and Palese, P. (1993). Glycosylation of Neuraminidase Determines the Neurovirulence of Influenza A/WSN/33 Virus. J. Virol. 67 (11), 6667-6673. doi:10.1128/JVI.67.11.6667-6673.1993

Lumb, F. E., Doonan, J., Bell, K. S., Pineda, M. A., Corbet, M., Suckling, C. J., et al. (2017). Dendritic Cells Provide a Therapeutic Target for Synthetic Small Molecule Analogues of the Parasitic Worm Product, ES-62. Sci. Rep. 7 (1), 1704-1713. doi:10.1038/s41598-017-01651-1

MacDonald, A. S., and Maizels, R. M. (2008). Alarming Dendritic Cells for Th2 Induction. J. Exp. Med. 205 (1), 13-17. doi:10.1084/jem.20072665

Maizels, R. M., Burke, J., and Denham, D. A. (1987). Phosphorylcholinebearing Antigens in Filarial Nematode Parasites: Analysis of Somatic Extracts, In-Vitro Secretions and Infection Sera from Brugia malayi and B. Pahangi. Parasite Immunol. 9 (1), 49-66. doi:10.1111/j.13653024.1987.tb00488.x

Maizels, R. M., and Yazdanbakhsh, M. (2008). T-cell Regulation in Helminth Parasite Infections: Implications for Inflammatory Diseases. T Cel Regul. Allergy Asthma Atopic Skin Dis. 94, 112-123. doi:10.1159/000154944

McVay, C. S., Bracken, P., Gagliardo, L. F., and Appleton, J. (2000). Antibodies to Tyvelose Exhibit Multiple Modes of Interference with the Epithelial Niche of Trichinella spiralis. Infect. Immun. 68 (4), 1912-1918. doi:10.1128/ IAI.68.4.1912-1918.2000

McVay, C. S., Tsung, A., and Appleton, J. (1998). Participation of Parasite Surface Glycoproteins in Antibody-Mediated Protection of Epithelial Cells against Trichinella spiralis. Infect. Immun. 66, 1941-1945. doi:10.1128/ IAI.66.5.1941-1945.1998

Medzhitov, R. (2007). Recognition of Microorganisms and Activation of the Immune Response. Nature 449 (7164), 819-826. doi:10.1038/nature06246

Melman, S. D., Steinauer, M. L., Cunningham, C., Kubatko, L. S., Mwangi, I. N., Wynn, N. B., et al. (2009). Reduced Susceptibility to Praziquantel Among Naturally Occurring Kenyan Isolates of Schistosoma Mansoni. Plos Negl. Trop. Dis. 3 (8), e504. doi:10.1371/journal.pntd.0000504

Meyvis, Y., Callewaert, N., Gevaert, K., Timmerman, E., Van Durme, J., Schymkowitz, J., et al. (2008). Hybrid N-Glycans on the Host Protective Activation-Associated Secreted Proteins of Ostertagia Ostertagi and Their
Importance in Immunogenicity. Mol. Biochem. Parasitol. 161 (1), 67-71. doi:10.1016/j.molbiopara.2008.05.004

Meyvis, Y., Geldhof, P., Gevaert, K., Timmerman, E., Vercruysse, J., and Claerebout, E. (2007). Vaccination against Ostertagia Ostertagi with Subfractions of the Protective ES-Thiol Fraction. Vet. Parasitol. 149 (3-4), 239-245. doi:10.1016/j.vetpar.2007.08.014

Munn, E. A., Smith, T. S., Graham, M., Tavernor, A. S., and Greenwood, C. A. (1993). The Potential Value of Integral Membrane Proteins in the Vaccination of Lambs against Haemonchus Conortus. Int. J. Parasitol. 23 (2), 261-269. doi:10.1016/0020-7519(93)90149-s

Nana-Djeunga, H. C., Bourguinat, C., Pion, S. D., Bopda, J., Kengne-Ouafo, J. A., Njiokou, F., et al. (2014). Reproductive Status of Onchocerca Volvulus after Ivermectin Treatment in an Ivermectin-Naïve and a Frequently Treated Population from Cameroon. Plos Negl. Trop. Dis. 8 (4), e2824. doi:10.1371/ journal.pntd.0002824

Naus, C. W. A., Van Remoortere, A., Ouma, J. H., Kimani, G., Dunne, D. W., Kamerling, J. P., et al. (2003). Specific Antibody Responses to Three Schistosome-Related Carbohydrate Structures in Recently Exposed Immigrants and Established Residents in an Area of Schistosoma Mansoni Endemicity. Infect. Immun. 71 (10), 5676-5681. doi:10.1128/IAI.71.10.56765681.2003

Newton, S. E., and Meeusen, E. N. T. (2003). Progress and New Technologies for Developing Vaccines against Gastrointestinal Nematode Parasites of Sheep. Parasite Immunol. 25 (5), 283-296. doi:10.1046/j.1365-3024.2003.00631.x

Nguyen, K., van Die, I., Grundahl, K. M., Kawar, Z. S., and Cummings, R. D. (2007). Molecular Cloning and Characterization of the Caenorhabditis elegans a1,3-fucosyltransferase Family. Glycobiology 17 (6), 586-599. doi:10.1093/ glycob/cwm023

Nisbet, A. J., Meeusen, E. N., González, J. F., and Piedrafita, D. M. (2016). Immunity to Haemonchus contortus and Vaccine Development. Adv. Parasitol. 93, 353-396. doi:10.1016/bs.apar.2016.02.011

Osei-Atweneboana, M. Y., Awadzi, K., Attah, S. K., Boakye, D. A., Gyapong, J. O., and Prichard, R. K. (2011). Phenotypic Evidence of Emerging Ivermectin Resistance in Onchocerca Volvulus. Plos Negl. Trop. Dis. 5 (3), e998. doi:10.1371/journal.pntd.0000998

Pineda, M. A., Lumb, F., Harnett, M. M., and Harnett, W. (2014). ES-62, a Therapeutic Anti-inflammatory Agent Evolved by the Filarial Nematode Acanthocheilonema Viteae. Mol. Biochem. Parasitol. 194 (1-2), 1-8. doi:10.1016/j.molbiopara.2014.03.003

Prasanphanich, N. S., Luyai, A. E., Song, X., Heimburg-Molinaro, J., Mandalasi, M., Mickum, M., et al. (2014). Immunization with Recombinantly Expressed Glycan Antigens from Schistosoma Mansoni Induces Glycan-specific Antibodies against the Parasite. Glycobiology 24 (7), 619-637. doi:10.1093/ glycob/cwu027

Prasanphanich, N. S., Mickum, M. L., Heimburg-Molinaro, J., and Cummings, R. D. (2013). Glycoconjugates in Host-Helminth Interactions. Front. Immunol. 4, 240. doi: $10.3389 /$ fimmu. 2013.00240

Reason, A. J., Ellis, L. A., Appleton, J. A., Wisnewski, N., Grieve, R. B., McNeil, M., et al. (1994). Novel Tyvelose-Containing Tri- and Tetra-Antennary N-Glycans in the Immunodominant Antigens of the Intracellular Parasite Trichinella spiralis. Glycobiology 4, 593-603. doi:10.1093/glycob/4.5.593

Reszka, N., Rijsewijk, F. A. M., Zelnik, V., Moskwa, B., and Bieńkowska-Szewczyk, K. (2007). Haemonchus contortus: Characterization of the Baculovirus Expressed Form of Aminopeptidase H11. Exp. Parasitol. 117 (2), 208-213. doi:10.1016/j.exppara.2007.03.018

Roberts, B., Antonopoulos, A., Haslam, S. M., Dicker, A. J., McNeilly, T. N., Johnston, S. L., et al. (2013). Novel Expression of Haemonchus contortus Vaccine Candidate Aminopeptidase H11 Using the Free-Living Nematode Caenorhabditis elegans. Vet. Res. 44 (1), 1-15. doi:10.1186/1297-9716-44-111

Robinson, K., Bellaby, T., Chan, W. C., and Wakelin, D. (1995). High Levels of protection Induced by a 40-mer Synthetic Peptide Vaccine against the Intestinal Nematode Parasite Trichinella spiralis. Immunology 86 (4), 495-498.

Rook, G. A. W. (2010). 99th Dahlem Conference on Infection, Inflammation and Chronic Inflammatory Disorders: Darwinian Medicine and the 'hygiene' or 'old Friends' Hypothesis. Clin. Exp. Immunol. 160 (1), 70-79. doi:10.1111/j.13652249.2010.04133.x

Rzepecka, J., Coates, M. L., Saggar, M., Al-Riyami, L., Coltherd, J., Tay, H. K., et al. (2014). Small Molecule Analogues of the Immunomodulatory Parasitic 
Helminth Product ES-62 Have Anti-allergy Properties. Int. J. Parasitol. 44 (9), 669-674. doi:10.1016/j.ijpara.2014.05.001

Rzepecka, J., Pineda, M. A., Al-Riyami, L., Rodgers, D. T., Huggan, J. K., Lumb, F. E., et al. (2015). Prophylactic and Therapeutic Treatment with a Synthetic Analogue of a Parasitic Worm Product Prevents Experimental Arthritis and Inhibits IL-1 $\beta$ Production via NRF2-Mediated Counter-regulation of the Inflammasome. J. Autoimmun. 60, 59-73. doi:10.1016/j.jaut.2015.04.005

Schulze, I. T. (1997). Effects of Glycosylation on the Properties and Functions of Influenza Virus Hemagglutinin. J. Infect. Dis. 176 (Suppl. ment_1), S24-S28. doi:10.1086/514170

Smit, C. H., van Diepen, A., Nguyen, D. L., Wuhrer, M., Hoffmann, K. F., Deelder, A. M., et al. (2015). Glycomic Analysis of Life Stages of the Human Parasite Schistosoma Mansoni Reveals Developmental Expression Profiles of Functional and Antigenic Glycan Motifs*. Mol. Cell Proteomics 14 (7), 1750-1769. doi:10.1074/mcp.M115.048280

Steinfelder, S., Andersen, J. F., Cannons, J. L., Feng, C. G., Joshi, M., Dwyer, D., et al. (2009). The Major Component in Schistosome Eggs Responsible for Conditioning Dendritic Cells for Th2 Polarization Is a T2 Ribonuclease (omega-1). J. Exp. Med. 206 (8), 1681-1690. doi:10.1084/jem.20082462

Suckling, C. J., Mukherjee, S., Khalaf, A. I., Narayan, A., Scott, F. J., Khare, S., et al. (2018). Synthetic Analogues of the Parasitic Worm Product ES-62 Reduce Disease Development in In Vivo Models of Lung Fibrosis. Acta tropica 185, 212-218. doi:10.1016/j.actatropica.2018.05.015

Sutherland, I. A., and Leathwick, D. M. (2011). Anthelmintic Resistance in Nematode Parasites of Cattle: a Global Issue? Trends Parasitol. 27 (4), 176-181. doi:10.1016/j.pt.2010.11.008

Szymanski, C. M., Burr, D. H., and Guerry, P. (2002). Campylobacter Protein Glycosylation Affects Host Cell Interactions. Infect. Immun. 70 (4), 2242-2244. doi:10.1128/IAI.70.4.2242-2244.2002

Taylor, M. E., Bezouska, K., and Drickamer, K. (1992). Contribution to Ligand Binding by Multiple Carbohydrate-Recognition Domains in the Macrophage Mannose Receptor. J. Biol. Chem. 267 (3), 1719-1726. doi:10.1016/s0021-9258(18)46005-x

Tundup, S., Srivastava, L., Norberg, T., Watford, W., and Harn, D. (2015). A Neoglycoconjugate Containing the Human Milk Sugar LNFPIII Drives Antiinflammatory Activation of Antigen Presenting Cells in a CD14 Dependent Pathway. PLoS ONE 10 (9), e0137495-19. doi:10.1371/journal.pone.0137495

van Die, I., Gomord, V., Kooyman, F. N., van den Berg, T. K., Cummings, R. D., and Vervelde, L. (1999). Core Alpha1-->3Ffucose Is a Common Modification of N-Glycans in Parasitic Helminths and Constitutes an Important Epitope for IgE from Haemonchus contortus Infected Sheep. FEBS Lett. 463 (1-2), 189-193. doi:10.1016/s0014-5793(99)01508-2

van Die, I., van Vliet, S. J., Nyame, A. K., Cummings, R. D., Bank, C. M. C., Appelmelk, B., et al. (2003). The Dendritic Cell-specific C-type Lectin DCSIGN Is a Receptor for Schistosoma Mansoni Egg Antigens and Recognizes the Glycan Antigen Lewis X. Glycobiology 13 (6), 471-478. doi:10.1093/glycob/ cwg052

van Liempt, E., van Vliet, S. J., Engering, A., García Vallejo, J. J., Bank, C. M. C., Sanchez-Hernandez, M., et al. (2007). Schistosoma Mansoni Soluble Egg Antigens Are Internalized by Human Dendritic Cells through Multiple C-type Lectins and Suppress TLR-Induced Dendritic Cell Activation. Mol. Immunol. 44 (10), 2605-2615. doi:10.1016/j.molimm.2006.12.012

Van Noort, K., Nguyen, D.-L., Kriechbaumer, V., Hawes, C., Hokke, C. H., Schots, A., et al. (2020). Functional Characterization of Schistosoma Mansoni Fucosyltransferases in Nicotiana Benthamiana Plants. Sci. Rep. 10 (1), 1-13. doi:10.1038/s41598-020-74485-Z

van Remoortere, A., van Dam, G. J., Hokke, C. H., van den Eijnden, D. H., van Die, I., Deelder, A., et al. (2001). Profiles of Immunoglobulin M (IgM) and IgG Antibodies against Defined Carbohydrate Epitopes in Sera of Schistosoma -Infected Individuals Determined by Surface Plasmon Resonance. Infect. Immun. 69 (4), 2396-2401. doi:10.1128/IAI.69.4.239610.1128/iai.69.4.23962401.2001

Van Remoortere, A., Vermeer, H. J., Van Roon, A. M., Langermans, J. A., Thomas, A. W., Wilson, R. A., et al. (2003). Dominant Antibody Responses to Fuca13GalNAc and Fuca1-2Fuca1-3GlcNAc Containing Carbohydrate Epitopes in
Pan troglodytes Vaccinated and Infected with Schistosoma Mansoni. Exp. Parasitol. 105 (3-4), 219-225. doi:10.1016/j.exppara.2003.12.005

van Stijn, C. M. W., van den Broek, M., Vervelde, L., Alvarez, R. A., Cummings, R. D., Tefsen, B., et al. (2010). Vaccination-induced IgG Response to Gala13GalNAc Glycan Epitopes in Lambs Protected against Haemonchus contortus challenge Infection. Int. J. Parasitol. 40 (2), 215-222. doi:10.1016/ j.ijpara.2009.07.009

van Vliet, S. J., van Liempt, E., Saeland, E., Aarnoudse, C. A., Appelmelk, B., Irimura, T., et al. (2005). Carbohydrate Profiling Reveals a Distinctive Role for the C-type Lectin MGL in the Recognition of Helminth Parasites and Tumor Antigens by Dendritic Cells. Int. Immunol. 17 (5), 661-669. doi:10.1093/ intimm/dxh246

Vervelde, L., Bakker, N., Kooyman, F. N. J., Cornelissen, A. W. C. A., Bank, C. M. C., Nyame, A. K., et al. (2003). Vaccination-induced protection of Lambs against the Parasitic Nematode Haemonchus contortus Correlates with High IgG Antibody Responses to the LDNF Glycan Antigen. Glycobiology 13 (11), 795-804. doi:10.1093/glycob/cwg107

Walsh, K. P., and Mills, K. H. G. (2013). Dendritic Cells and Other Innate Determinants of $\mathrm{T}$ Helper Cell Polarisation. Trends Immunology 34 (11), 521-530. doi:10.1016/j.it.2013.07.006

Weaver, C. T., Hatton, R. D., Mangan, P. R., and Harrington, L. E. (2007). IL-17 Family Cytokines and the Expanding Diversity of Effector T Cell Lineages. Annu. Rev. Immunol. 25, 821-852. doi:10.1146/ annurev.immunol.25.022106.141557

Weis, W. I., Taylor, M. E., and Drickamer, K. (1998). The C-type Lectin Superfamily in the Immune System. Immunol. Rev. 163 (1), 19-34. doi:10.1111/j.1600-065x.1998.tb01185.x

Wilbers, R. H. P., Westerhof, L. B., Van Noort, K., Obieglo, K., Driessen, N. N., Everts, B., et al. (2017). Production and Glyco-Engineering of Immunomodulatory Helminth Glycoproteins in Plants. Sci. Rep. 7, 45910. doi:10.1038/srep45910

Yang, Y. Y. M., Wilson, R. A., Thomas, S. R. L., Kariuki, T. M., van Diepen, A., and Hokke, C. H. (2019). Micro Array-Assisted Analysis of Anti-schistosome Glycan Antibodies Elicited by Protective Vaccination with Irradiated Cercariae. J. Infect. Dis. 219 (10), 1671-1680. doi:10.1093/infdis/jiy714

Zaccone, P., Fehervari, Z., Phillips, J. M., Dunne, D. W., and Cooke, A. (2006). Parasitic Worms and Inflammatory Diseases. Parasite Immunol. 28 (10), 515-523. doi:10.1111/j.1365-3024.2006.00879.x

Zande, H. J. P., Gonzalez, M. A., Ruiter, K., Wilbers, R. H. P., García-Tardón, N., Huizen, M., et al. (2021). The Helminth Glycoprotein omega-1 Improves Metabolic Homeostasis in Obese Mice through Type 2 Immunityindependent Inhibition of Food Intake. FASEB j. 35 (2), e21331. doi:10.1096/fj.202001973R

Zelensky, A. N., and Gready, J. E. (2005). The C-type Lectin-like Domain Superfamily. FEBS J. 272 (24), 6179-6217. doi:10.1111/j.17424658.2005.05031.x

Conflict of Interest: The authors declare that the research was conducted in the absence of any commercial or financial relationships that could be construed as a potential conflict of interest.

Publisher's Note: All claims expressed in this article are solely those of the authors and do not necessarily represent those of their affiliated organizations, or those of the publisher, the editors and the reviewers. Any product that may be evaluated in this article, or claim that may be made by its manufacturer, is not guaranteed or endorsed by the publisher.

Copyright $\odot 2022$ Bunte, Schots, Kammenga and Wilbers. This is an open-access article distributed under the terms of the Creative Commons Attribution License (CC $B Y$ ). The use, distribution or reproduction in other forums is permitted, provided the original author(s) and the copyright owner(s) are credited and that the original publication in this journal is cited, in accordance with accepted academic practice. No use, distribution or reproduction is permitted which does not comply with these terms. 